\title{
Analise dos benefícios da cinesioterapia laboral a curto, médio e longo prazo: uma revisão de literatura
}

\author{
Analysis of the benefits of labor kinesiotherapy short, medium and \\ soon-term: a literature review \\ Analisis de los beneficios de la cinesioterapia laboral a corto, medio y largo \\ plazo: una revisión de literatura \\ Leandro IACKSTET ${ }^{1}$ \\ Ana Carolina Barbosa Faria GONÇALVES ${ }^{2}$ \\ Silvia Fiorillo Cabrera SOARES ${ }^{3}$
}

${ }^{l}$ Graduação em Fisioterapia pela Faculdade Anhanguera Educacional do estado de São Paulo, 17021-005 Bauru-SP, Brasil

${ }^{2}$ Mestre em Engenharia Mecânica pela Universidade de São Paulo USP de São Carlos, Docente na Faculdade Anhanguera Educacional 17021-005 Bauru - SP, Brasil

${ }_{3}^{3}$ Mestre em Fisioterapia pela Universidade do Estado de Santa Catarina -CEFID, Laboratório de Biomecânica, 88080-350 Florianopolis - SC, Brasil

\section{Resumo}

A revolução industrial trouxe o desenvolvimento e o capitalismo para a humanidade, a busca pelo lucro promoveu o aumento na jornada de trabalho e consigo as lesões e doenças relacionadas ao trabalho. A falta de organização associada ao grande esforço do trabalhador ocasionou o cansaço físico e mental o que o tornou suscetível a desenvolver LER/DORT. Devido a isso, o fisioterapeuta atua nas empresas aplicando a cinesioterapia laboral para prevenir e minimizar tais problemas de saúde e promover o bem estar, saúde e produtividade para a empresa. Dentro deste contexto este estudo tem como objetivo realizar uma revisão de literatura a fim de verificar os benefícios da cinesioterapia laboral a curto, médio e longo prazo, e verificar se a implantação de um projeto de cinesioterapia laboral promove melhora nas condições de trabalho, bem como a redução da fadiga no trabalho e aumenta da eficácia e produtividade. Como metodologia foi realizada uma revisão de literatura, com pesquisa em bases de dados e os artigos selecionados foram analisados. Como resultados, verificou-se que a prática da cinesioterapia laboral traz benefícios ao trabalhador verificados em curto prazo (à partir de um mês de implantação), melhorando a saúde e a qualidade de vida dos trabalhadores, promovendo impacto positivo no seu dia a dia e em sua jornada de trabalho, além de contribuir para a empresa no sentido de maior eficácia no trabalho e redução do absenteísmo e afastamentos médicos.

Descritores: Técnicas de Exercício e de Movimento; Exposição Ocupacional; Ergonomia; Revisão.

\section{Abstract}

The industrial revolution brought development and capitalism for humanity, the profit motive promoted the increase in working hours and with injuries and work-related diseases. The lack of organization associated with great effort caused the worker's physical and mental fatigue which made him susceptible to developing RSI / MSDs. Because of this, the therapist acts in businesses applying labor kinesiotherapy to prevent and minimize such health problems and promote the welfare, health and productivity for the company. Within this context, this study aims to conduct a literature review in order to verify the benefits of labor kinesiotherapy in the short, medium and long term, and verify that the implementation of a labor kinesiotherapy project promotes improvement in working conditions and reducing fatigue and increases work efficiency and productivity. The methodology was carried out a literature review, with research in databases and selected articles were analyzed. As a result, it was found that the practice of labor kinesiotherapy benefits the short-term checked worker (starting at one month of implantation), improving health and quality of life of workers, promoting positive impact on their daily lives and in your workday, and contribute to the company towards greater efficiency at work and reducing absenteeism and medical leaves.

Descriptors: Exercise Movement Techniques; Occupational Exposure; Ergonomics; Review.

\section{Resumen}

La revolución industrial trajo el desarrollo y el capitalismo para la humanidad, la búsqueda por el lucro promovió el aumento en la jornada de trabajo y consigo las lesiones y enfermedades relacionadas al trabajo. La falta de organización asociada al gran esfuerzo del trabajador ocasionó el cansancio físico y mental lo que lo hizo susceptible a desarrollar LER / DORT. Debido a esto, el fisioterapeuta actúa en las empresas aplicando la cinesioterapia laboral para prevenir y minimizar tales problemas de salud y promover el bienestar, salud y productividad para la empresa. En este contexto este estudio tiene como objetivo realizar una revisión de literatura a fin de verificar los beneficios de la cinesioterapia laboral a corto, mediano y largo plazo, y verificar si la implantación de un proyecto de cinesioterapia laboral promueve mejora en las condiciones de trabajo, así como la reducción de la fatiga en el trabajo y aumenta la eficacia y la productividad. Como metodología se realizó una revisión de literatura, con investigación en bases de datos y los artículos seleccionados fueron analizados. Como resultados, se verificó que la práctica de la cinesioterapia laboral trae beneficios al trabajador verificados a corto plazo (a partir de un mes de implantación), mejorando la salud y la calidad de vida de los trabajadores, promoviendo impacto positivo en su día a día y, en su jornada de trabajo, además de contribuir a la empresa en el sentido de mayor eficacia en el trabajo y reducción del absentismo y alejamientos médicos.

Descriptores: Técnicas de Ejercicio con Movimientos; Exposición Ocupacional; Ergonomía; Revisión.

\section{INTRODUÇÃO}

A Revolução Industrial foi um marco para evolução da humanidade, promovendo mudanças rápidas nos meios de produção. Esse impulso aconteceu de forma veloz e a busca pelo lucro levou os trabalhadores a aumentar as jornadas e horários de trabalho, com duração de até 15 horas diárias, gerando um ciclo prolongado de cansaço físico, mental, insatisfação, desmotivação e incapacidades ${ }^{1,2}$.

Nesta época os trabalhadores não dispunham de um programa de proteção de acidentes, apoio social ou qualquer tipo de benefício e era comum que os acidentes de trabalhos gerassem incapacidades e mutilações.

$\mathrm{Na}$ tentativa de aliviar os esforços físicos houve uma reorganização no trabalho que passou a ser executado por meio de máquinas comandadas pelos operários, reduzindo, assim, o esforço físico pesado. Porém, surgiram lesões por esforços repetitivos, a LER, tornando o trabalhador mais suscetível de sofrer um acidente de trabalho ou desenvolver DORT (distúrbios osteomusculares relacionados com o trabalho $)^{2,3}$.

Apesar de serem duas siglas diferentes a LER e DORT são utilizadas em conjunto, pois ambas representam, em grande número, as doenças ocupacionais ${ }^{4}$. Para Renner ${ }^{5}$ é difícil apontar uma causa específica para o aparecimento de problemas e distúrbios osteomusculares na saúde dos trabalhadores, independentemente de suas atividades laborais. Renner ainda cita que medidas simples como adaptar o posto de trabalho e adequar os padrões posturais por meio de ação educativas poderiam solucionar o problema.

Os problemas de LER/DORT estão diretamente relacionados com a produtividade e a saúde do trabalhador. 
Uma vez acometido o trabalhador passa a apresentar conflitos sociais e econômicos, além da sintomatologia de dor, questões financeiras pessoal, da empresa e dos órgãos públicos acabam sendo envolvidos neste processo ${ }^{6,7}$.

A Ergonomia é uma disciplina científica que tem como principal objetivo otimizar o bem estar humano e o desempenho global do sistema ${ }^{8}$. Na prática, ela busca dar condições favoráveis para que o ser humano possa adaptar e organizar seu ambiente de trabalho. Para tal execução se faz necessário conhecimentos nas áreas de anatomia, fisiologia e psicologia ${ }^{1,5,9,10}$.

Segundo Braga $^{9}$ a ergonomia visar analisar e identificar as situações inadequadas dentro de um ambiente de trabalho, sejam elas da estrutura ou do movimento, e, ao adequar essas situações, tornar o trabalho mais eficiente se preocupando com a saúde, conforto, segurança do trabalho, qualidade e produtividade.

Bernadi ${ }^{1}$ aponta quatro formas de abordagem dentro da ergonomia: a ergonomia de concepção, baseada no projeto de execução de um ambiente de trabalho, o qual será criado de forma que satisfaça às necessidades do trabalhador, para que esse consiga executar sua tarefa da melhor forma possível; a ergonomia de correção, a qual corresponde na adaptação do ambiente de trabalho já criado e avaliado ao homem; a ergonomia de conscientização representada pela implantação de informações educativas por meio de palestras e materiais impressos, por exemplo; e por fim a ergonomia de participação, representada por um comitê interno responsável por manter as atividades ergonômicas presentes e ativas dentro de uma empresa.

$\mathrm{Na}$ prática a ergonomia vai atuar realizando, quando necessário, alterações no ambiente físico e nos equipamentos, de forma que o trabalhador se sinta confortável e seguro, aumentando seu desempenho; introduzindo programas de rodízio de funções; pausas durante as jornadas de trabalho; e organizando as atividades laborais ${ }^{1,7,15}$.

A cinesioterapia laboral (CL) é uma atividade física que visa à prevenção de doenças ocupacionais e é realizada no próprio local de trabalho, durante um período curto de tempo, que varia entre 8 e 12 minutos, dentro da jornada diária e deve ser realizada 3 vezes por semana ou diariamente ${ }^{7,12}$.

Para realizar a CL é necessário analisar a biomecânica da atividade laboral, assim como as posturas adotadas e a partir destas informações elaborar uma série de exercícios físicos composta por alongamentos, fortalecimentos, exercícios de coordenação, relaxamento dentre outros que envolvam os principais músculos e articulações requisitadas durante o trabalho ${ }^{1}$.

Segundo Maciel $^{7}$ a CL pode classificada de acordo com o período a qual é aplicada em preparatória, compensatória e de relaxamento. A CL preparatória, composta por exercícios de coordenação motora, equilíbrio, concentração, flexibilidade e resistência muscular é aplicada no início da jornada de trabalho e tem como objetivo preparar as estruturas osteomusculares que serão requisitadas durante a jornada de trabalho. A CL compensatória utiliza exercícios de alongamento, posturais, respiratórios e de flexibilidade, é realizada durante a jornada de trabalho, visando uma pausa ativa que alivie tensões. Finalizando, a CL de relaxamento, que utiliza exercícios respiratórios, exercícios de alongamento e flexibilidade e, em alguns casos, até a meditação ${ }^{13-16}$, é realizada no final da jornada de trabalho com o objetivo de reduzir ou eliminar as tensões adquiridas durante o dia, reduzindo assim o estresse.

Com isso, o funcionário e a empresa têm inúmeros benefícios, reduzindo os afastamentos e quadros álgicos ${ }^{7,17}$.

\section{MATERIAL E MÉTODO}

Este estudo constitui de uma revisão da literatura especializada. O levantamento literário foi realizado entre março de 2015 e novembro de 2015, no qual foram consultados livros e periódicos presentes na Biblioteca da Universidade Anhanguera Educacional de Bauru (SP), e por artigos científicos selecionados através de busca no banco de dados do Scielo, Medline, Bireme e Google Acadêmico. Foram selecionados os artigos do ano de 2009 a 2015, e a pesquisa dos artigos foi realizada entre setembro e novembro de 2015 utilizando os descritores: Técnicas de Exercício e de Movimento, Exposição Ocupacional e Ergonomia Os critérios de inclusão para os estudos encontrados foram à abordagem da cinesioterapia laboral a curto, médio e longo prazo, independente de sua classificação, e estudos que abordassem o efeito dos tipos de cinesioterapia laboral. Foram excluídos estudos que relatavam o emprego de outras modalidades de tratamento, que não a cinesioterapia laboral e suas modalidades.

\section{RESULTADOS}

Foram encontrados $15 \operatorname{artigos}^{12}, 15,18-30$ nas bases de dados consultadas que versavam sobre a utilização da cinesioterapia laboral na prevenção da saúde do trabalhador, segundo os critérios de inclusão. As características dos estudos selecionados se encontram no Quadro 1.

Esses estudos avaliaram a efetividade e os tipos de cinesioterapia laboral, mostrando que a CL proporciona vários benefícios ao funcionário, ilustrados na Figura 1. A melhora da dor e do desempenho foram os benefícios mais citados pelos autores em $24 \%$ dos estudos, seguida da melhora da saúde e bem estar em $23 \%$, comprovando a eficácia da CL. A diminuição do estresse foi citada por $10 \%$ dos autores e a motivação por $7 \%$.

Quadro 1: Características dos estudos selecionados

\begin{tabular}{|c|c|c|c|c|c|}
\hline Autores & $\mathbf{n}$ & Tipo de CL & $\begin{array}{c}\begin{array}{c}\text { Frequência } \\
\text { semanal }\end{array} \\
\end{array}$ & $\begin{array}{c}\text { Duração da } \\
\text { CL }\end{array}$ & $\begin{array}{c}\begin{array}{c}\text { Duração da } \\
\text { pesquisa }\end{array} \\
\end{array}$ \\
\hline $\begin{array}{l}\text { Dartora } \\
\text { Santos }^{12}\end{array}$ & 8 & Preparatória & 3 & 15 minutos & 5 Meses \\
\hline $\begin{array}{l}\text { Pedroso e } \\
\text { Parizotto }^{15}\end{array}$ & 42 & Não especificado & $\begin{array}{c}\text { Não } \\
\text { especificado }\end{array}$ & $\begin{array}{c}\text { Não } \\
\text { especificado }\end{array}$ & 2 Meses \\
\hline $\begin{array}{l}\text { Bittencourt } \\
\text { et al. }{ }^{18}\end{array}$ & 50 & Compensatória & 2 & 15 minutos & 2 Meses \\
\hline $\begin{array}{l}\text { Brito }{ }^{\mathrm{e}} \\
\text { Martins }^{19}\end{array}$ & 10 & Compensatória & 3 & 15 minutos & 2 Meses \\
\hline $\begin{array}{l}\text { Cadotti et } \\
\text { al. }^{20}\end{array}$ & 15 & Preparatória & 3 & 15 minutos & 3 Meses \\
\hline $\begin{array}{l}\text { Costa et } \\
\text { al. }^{21}\end{array}$ & 30 & $\begin{array}{c}\text { Preparatória, } \\
\text { Compensatória e } \\
\text { Relaxante }\end{array}$ & 3 & 15 minutos & 2 Meses \\
\hline $\begin{array}{l}\text { Godin et } \\
\text { al. }^{22}\end{array}$ & 22 & Não especificado & 2 & $\begin{array}{c}\text { Não } \\
\text { especificado }\end{array}$ & 1 Mês \\
\hline $\begin{array}{l}\text { Oliveira e } \\
\text { Marques }^{23}\end{array}$ & 20 & Preparatória & 2 & $\begin{array}{l}10 \text { a } 15 \\
\text { minutos }\end{array}$ & 3 Meses \\
\hline 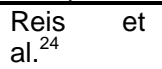 & 31 & Compensatória & 5 & 15 minutos & 18 Meses \\
\hline $\begin{array}{l}\text { Sakamoto } \\
\text { et al. }^{25}\end{array}$ & 30 & Compensatória & 3 & 10 minutos & 4 meses \\
\hline Santos $^{26}$ & 8 & Não especificado & 3 & 15 minutos & 3 Meses \\
\hline $\begin{array}{l}\text { Sedrez et } \\
\text { al. }{ }^{27}\end{array}$ & 43 & Compensatória & $\begin{array}{c}\text { Não } \\
\text { especificado }\end{array}$ & $\begin{array}{c}\text { Não } \\
\text { especificado }\end{array}$ & 36 meses \\
\hline Silva ${ }^{28}$ & 30 & Preparatória & 3 & 15 minutos & 1 Mês \\
\hline $\begin{array}{l}\text { Silveira et } \\
\text { al. }^{29}\end{array}$ & 5 & $\begin{array}{c}\text { Preparatória, } \\
\text { Compensatória e } \\
\text { Relaxante }\end{array}$ & 5 & $\begin{array}{l}10 \text { a } 15 \\
\text { minutos }\end{array}$ & 3 Meses \\
\hline $\begin{array}{l}\text { Souza } \\
\text { Bezerra }^{30}\end{array}$ & 20 & Não especificado & $\begin{array}{c}\text { Não } \\
\text { especificado }\end{array}$ & $\begin{array}{c}\text { Não } \\
\text { especificado }\end{array}$ & $\begin{array}{c}\text { Não } \\
\text { especificado }\end{array}$ \\
\hline
\end{tabular}
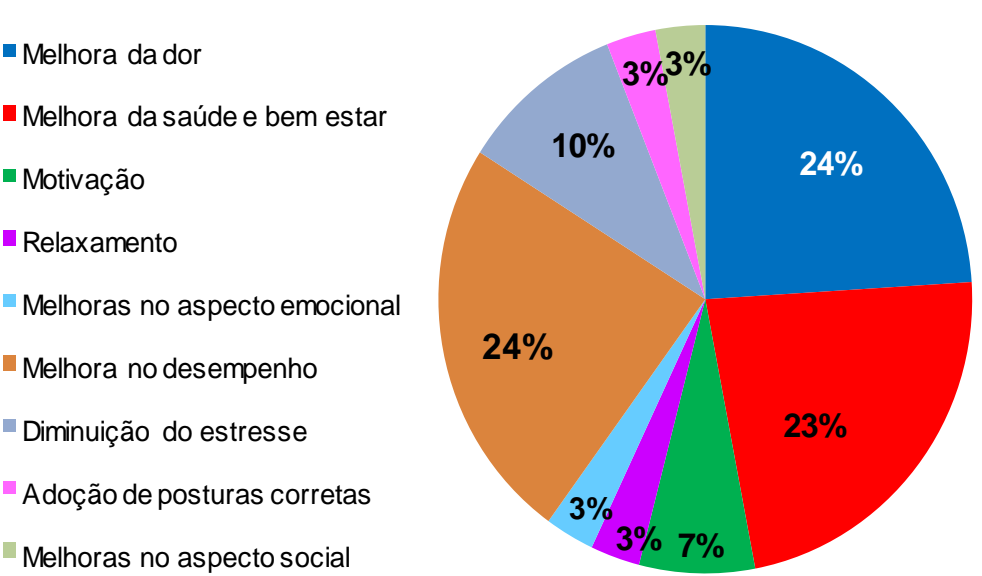

Figura 1: Benefícios da cinesioterapia laboral (Fonte: dados da pesquisa, 2018). 
Com relação à dor, um dos principais motivos de faltas de funcionário, houve melhora significativa, como ilustrado pela Figura 2, que apresenta o autor e a porcentagem de redução da dor. Para o empregador este é um dado importante por reduzir o absenteísmo. Além da redução da dor, outros resultados positivos são citados. A melhora no desempenho durante o trabalho foi um dos resultados mais positivo encontrado pelos autores, como apresentado na Figura 3. Nos 15 estudos selecionados, 46,66\% dos autores apontaram a melhora da saúde e do bem estar como efeito benéfico da CL (Figura 4). Com relação ao tempo dos resultados obtidos, a maioria foi obtida em curto prazo, comprovando a eficiência da CL aplicada em curtos períodos de tempo. Apenas um autor $(6,66 \%)$ não informou o tempo de pesquisa, porém, pelos resultados alcançados foi incluído na revisão (Figura 5).

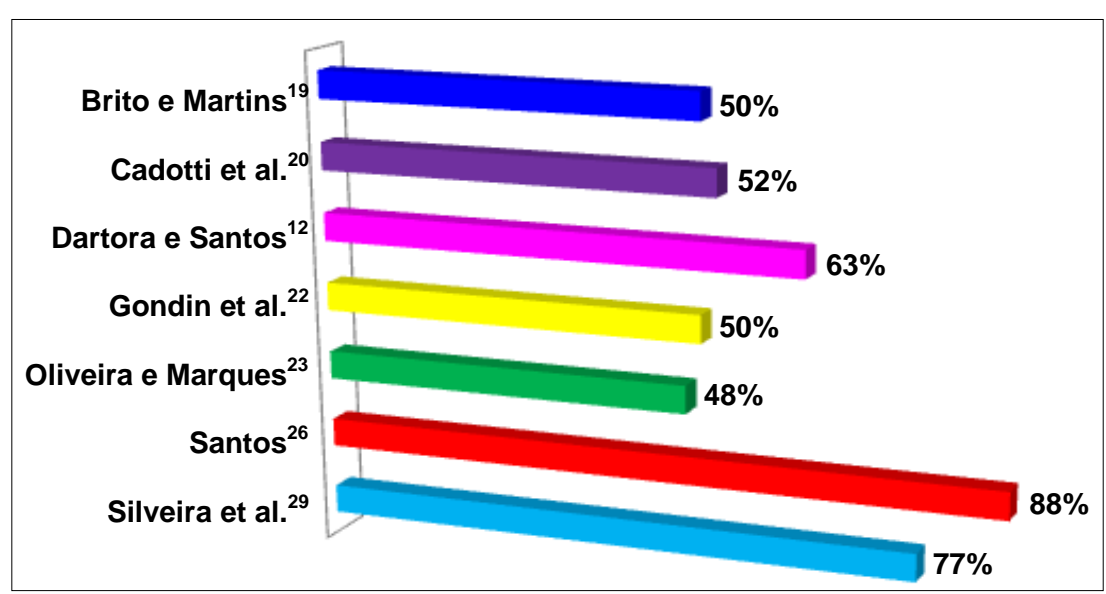

Figura 2: Redução das queixas físicas (Fonte: dados da pesquisa, 2018).

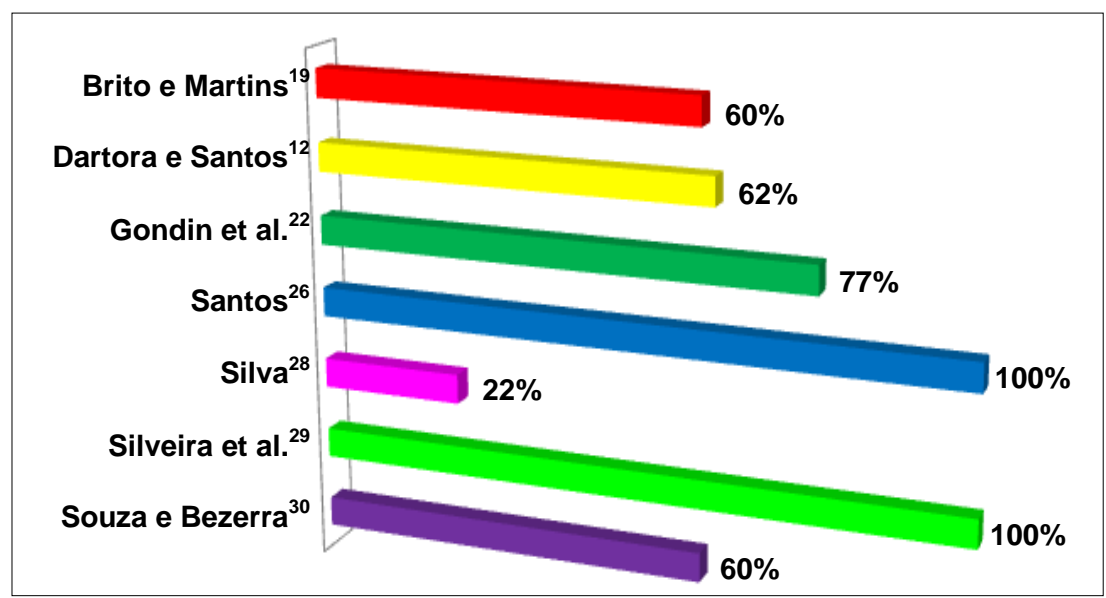

Figura 3: Melhora no desempenho

(Fonte: dados da pesquisa, 2018)

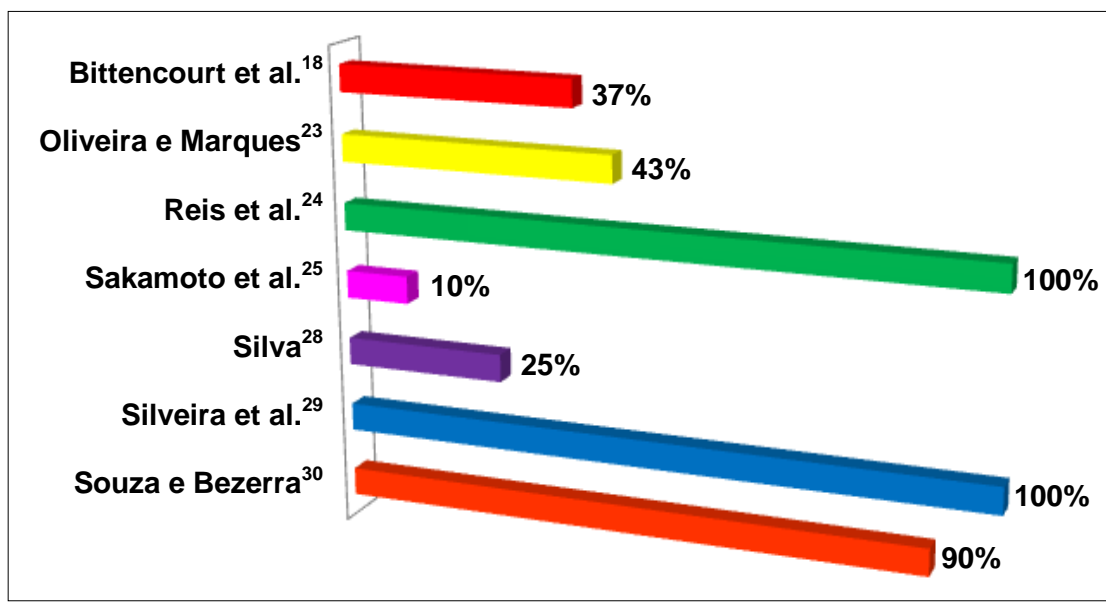

Figura 4: Melhora na saúde e bem estar. (Fonte: dados da pesquisa, 2018)

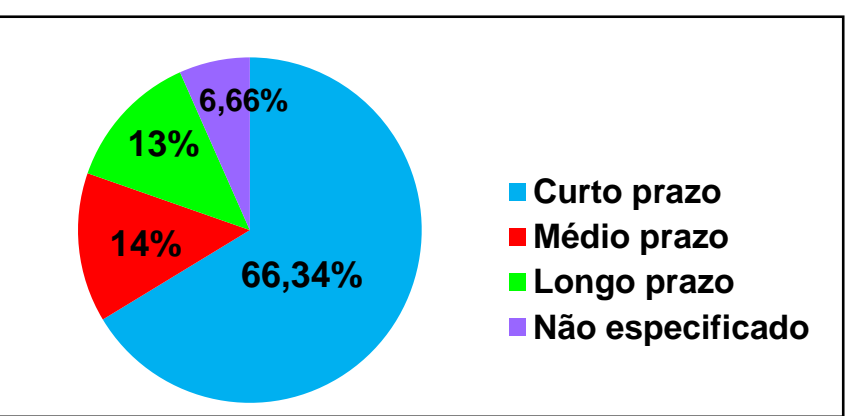

Figura 5: Tempo para obtenção dos resultados. (Fonte: dados da pesquisa, 2018).

\section{DISCUSSÃO}

Sakamoto et al. ${ }^{25}$ conduziram um estudo em uma empresa que não havia programa de atividade física e avaliaram 30 funcionários de ambos os sexos. Realizaram exercícios laborais, três vezes por semana, com duração de 10 minutos, contendo alongamentos, dinâmicas, resistência muscular localizada, massagens e relaxamento. Utilizaram como avaliação o teste de Inventário para Dor de Wisconsin (reduzido). Como resultados, observaram um aumento de $10 \%$ no número de amostras que melhoraram o conceito sobre sua saúde considerando-a excelente após três meses de prática da CL.

No estudo transversal com abordagem quantitativa de Godim et al. $^{22}$ foi realizada uma coleta de dados em um hospital da rede pública de Fortaleza, durante um mês de CL, em cinco setores, totalizando 22 amostras, sendo a maioria dos participantes do sexo feminino. Os resultados da avaliação pré-cinesioterapia laboral mostraram que, dentre as regiões corporais de dores, a mais frequente foi a dor nas costas, afetando 20 funcionários; e em seguida as dores nas pernas, afetando 17 dos 22 funcionários, além do desgaste físico que foi citado como terceiro problema relacionado ao trabalho realizado. Após o programa de cinesioterapia laboral, os resultados indicaram que $54 \%$ dos funcionários começaram a fazer os exercícios fora do ambiente de trabalho. Além disso, $77 \%$ relataram melhorias do desempenho no próprio trabalho, pois se sentiam mais dispostos a executar suas atividades; 54\% relataram uma melhoria postural; e 50\% relataram diminuição das dores causadas pelo trabalho. Com a análise dos resultados os autores comprovaram estatisticamente a eficácia da cinesioterapia no ambiente de trabalho.

Visando verificar qual CL traz mais benefícios e qual influencia mais na qualidade de vida, Costa et al. ${ }^{21}$ estudaram 30 funcionários de uma empresa de construção civil, no cargo de auxiliar de serviços gerais, e com faixa etária de 20 a 40 anos. Foi aplicado o questionário SF-36 avaliando a qualidade de vida, antes do início do programa e ao final de dois meses de CL, com duração de 15 minutos e três vezes semanais, divididos em grupos de Ginástica Preparatória (GP); Ginástica Compensatória (GC); e Ginástica de Relaxamento (GR). Ao ser analisado os três tipos de CL, os autores notaram que ambas trazem benefícios em todos os aspectos, porém na GP houve uma melhora estatisticamente comprovada no aspecto dor; na GC somente a limitação por aspectos físicos, aspectos sociais e limitação por aspectos emocionais; e na GR nenhuma melhora estatisticamente comprovada, concluindo que não há diferença estatística entre os tipos de laboral, mas relacionado aos aspectos da saúde do trabalhador e melhorias para a empresa, os autores acharam resultados significantes.

No estudo de Brito e Martins ${ }^{19} 10$ participantes do programa de CL foram entrevistados após 24 aulas de CL compensatória. Com a aderência à $\mathrm{CL}$, os resultados indicaram que houve redução de dores corporais visto que $50 \%$ relataram melhora com o programa. Metade dos entrevistados relatou que se sentia sem disposição para as atividades do dia a dia e, após a GL, constataram maior ânimo e disposição; e $60 \%$ dos entrevistados relataram melhoria do relacionamento interpessoal. Houve melhora, também, da flexibilidade do tronco e quadril, devido aos alongamentos executados na CL, e mudança do estilo de vida, ambos sendo citados por $50 \%$ dos entrevistados.

Em uma CL com duração de 15 minutos, no período da manhã e composta por 31 funcionários, que a executam cinco vezes por semana, Reis et al. ${ }^{24}$ obtiveram sua amostra aplicando um questionário com quatro questões. Na primeira questão, $100 \%$ dos funcionários avaliados responderam que a $\mathrm{CL}$ ajudou a melhorar o bem estar diário. Na segunda questão, $85 \%$ dos funcionários avaliados disseram que a CL 
alterou seu estilo de vida. Na terceira questão, onde só responderam os funcionários que responderam sim na questão anterior, $20 \%$ afirmaram que começaram a se exercitar com mais frequência; $46 \%$ começaram a realizar exercícios da CL mesmo quando não tinha; $20 \%$ começaram a se alongar mais em casa antes de atividades e quando relatavam dores; e 14\% passaram a vivenciar os ensinamentos em palestras e adotar as sugestões para melhorar a qualidade de vida. Já na quarta questão, $88 \%$ dos servidores relataram que já ensinaram a amigos ou familiares, ou conversaram sobre algum exercício/conhecimento aprendido nas sessões de CL.

Bittencourt et al. ${ }^{18}$ selecionaram uma empresa onde os funcionários trabalhavam na posição sentada, realizando movimentos repetitivos e simultâneos e que já possuía um programa interno de qualidade de vida para seus funcionários. A análise foi composta por 50 funcionários de setores que possuíam o maior índice de afecções osteomusculares e emocionais, e que praticavam a CL compensatória. Foi aplicado o questionário SF-36 antes e após o programa de CL, que foi realizado duas vezes por semana, durante dois meses, e com duração de 15 minutos cada. Dos oito aspectos investigados, a capacidade funcional, o estado geral de saúde, a vitalidade e os aspectos sociais apresentaram uma melhora significativa, comprovando que a CL compensatória interferiu de maneira positiva na qualidade de vida dos funcionários.

No estudo de Dartora e Santos ${ }^{12}$ foram analisados oito funcionários de uma empresa de limpeza e urbanização de pequeno porte do vale de Taquari, após 24 sessões de CL preparatória, com duração de 15 minutos. Como resultado, $62,5 \%$ dos participantes que referiram dor antes da CL apresentaram diminuição dela após o final do programa, considerando que o grau de dor variou de três a cinco na escala visual analógica da dor (EVA) na primeira avaliação, e diminuiu para grau um a três na avaliação final. Observaram também que, na reavaliação, não houve mudança no local da dor, apenas diminuição da intensidade. Além disso, 87,5\% dos participantes entendem as práticas de ginástica laboral como agradáveis; $62,5 \%$ referiram que elas interferem no dia de trabalho com melhor desempenho físico; 37,5\% relataram que se sentem mais dispostos após a realização dos exercícios; e $100 \%$ dos participantes consideram importante a continuidade do programa.

Já Silva ${ }^{28}$ selecionou 30 professores de um centro de educação infantil e aplicou um questionário com perguntas abertas e fechadas, pré e pós quatro semanas de CL preparatória, sendo executadas três vezes por semana. Como resultados, $100 \%$ dos participantes relataram ter tido benefícios com a CL, sendo que $22 \%$ dos docentes afirmaram que após a aula de CL sentiram disposição, alegria e motivação; $25 \%$ afirmaram a sensação de relaxamento e bem estar; e 53\% ressaltaram a diminuição do estresse como maior benefício ofertado pelo programa. Além disso, $40 \%$ dos docentes disseram que a execução dos exercícios proporcionaram relaxamento e disposição para o trabalho, já os outros $60 \%$ optam em dizer que essas aulas proporcionam motivação, equilíbrio e diminuição do estresse ocupacional.

Cadotti et al. ${ }^{20}$, por meio de um grupo experimental e um grupo controle, com um total de 30 trabalhadores escolhidos por meio de sorteio, aplicaram um questionário referente a dor e postura, antes e depois de três meses de CL preparatória, que continha 15 minutos, sendo executada três vezes por semana, com exercícios de alongamentos, mobilização articular, flexibilidade, resistência e relaxamento. Os resultados demonstraram que a CL foi eficaz na diminuição da intensidade e frequência da dor, e na correção dos hábitos posturais durante o trabalho, melhorando a postura sentada dos funcionários.

No estudo de Oliveira e Marques ${ }^{23}$, 20 sujeitos do setor de limpeza de uma universidade foram submetidos a um programa de CL preparatória por três meses, sendo executadas duas vezes por semana. Foram avaliadas as dores no corpo, o desconforto durante a jornada de trabalho, o sono, o nível de estresse, as doenças e atividades da vida diária. Os principais resultados desse estudo mostraram que houve uma redução de $48 \%$ de funcionários que iniciavam o expediente com dores nas costas. Além disso, $47 \%$ obtiveram melhorias na qualidade do sono e houve uma melhora significativa no bem estar de $42 \%$, deixando evidente que os benefícios da CL contribuem direta e indiretamente na melhoria da qualidade de vida dentro do ambiente de trabalho, nas relações interpessoais e na redução de acidentes de trabalhos por lesões, promovendo saúde e melhores condições de trabalho para o ser humano.

No trabalho de Sedrez et al. ${ }^{27}$ a amostra foi constituída por 43 funcionários de uma universidade, sendo divididos entre grupo controle $(n=12)$ e experimental $(n=31)$. Foram avaliados pré e pós CL, sendo que somente o grupo experimental participou das sessões de CL por 36 meses consecutivos. Foi utilizado um questionário com questões sobre dor, quantidade de dor e qualidade de vida. Os resultados da comparação dos períodos de pré e pósexperimento demonstram que houve diferença significativa apenas para o grupo experimental, sendo observada diminuição na quantidade de dor e melhora na qualidade de vida nesse grupo, indicando que o programa de CL gerou efeitos positivos, proporcionando benefícios às pessoas que $\mathrm{o}$ aderiram.

Santos $^{26}$ analisou oito professores do sexo feminino, de uma escola de ensino fundamental, pré e pós 17 sessões de CL com duração de 15 minutos, visando alongamentos e relaxamentos. A primeira questão perguntava se o programa de CL influenciou na sua motivação profissional, fazendo com que tivesse aplicado pelo menos uma aula diferente em sala que não tinha trabalhado anteriormente com os alunos para poupar-se fisicamente. Como resultado a essa questão, observou-se que $100 \%$ assinalaram a resposta que se sentiram mais motivadas durante o programa e fizeram alguma atividade diferente em sala. $\mathrm{O}$ segundo questionamento mostrou que $87,5 \%$ das voluntárias sentiram alguma forma de melhora na dor/tensão e também na disposição durante seu trabalho com a aplicação da CL, e $100 \%$ indicariam o programa de CL a outros profissionais, mostrando que a intervenção da CL melhora a motivação pessoal e profissional dos profissionais, pois todas as voluntárias responderam que aplicaram pelo menos uma aula diferente durante o programa de ginastica laboral, o que facilita a interação professor-aluno e favorece a troca de conhecimentos em sala de aula.

O estudo de Silveira et al. ${ }^{29}$ analisou a influência da CL na percepção das dores em trabalhadoras de um laboratório farmacêutico, com média de idade de 33,8 anos. As cinco funcionárias avaliadas tinham no mínimo três anos de empresa, com uma carga horária de nove horas diária, sendo que, dessas, uma hora era para descanso, alimentação e hidratação. Foram marcados 18 tender points e avaliados mediante a pressão por 20 segundos ou até o relato da sensibilidade, pré e pós três meses de CL, contendo cinco sessões semanais de ginástica de aquecimento (10-15min diários), cinco de ginástica de pausa (10-15min diários), e três sessões semanais de ginástica compensatória (30-60min por sessão) executadas em uma academia na própria empresa. Os resultados mostram que, após a CL, as funcionárias obtiveram uma melhora no quadro de dor, reduzindo em $76 \%$ as suas queixa. Além disso, houve uma redução de quase $100 \%$ no absenteísmo, comprovando que, além de reduzir as queixas de dor, proporciona, também, o bem estar do funcionário, reduzindo assim as faltas.

Em um estudo recente, realizado em três empresas comercias do centro de Dourados (MS), Pedroso e Parizotto ${ }^{15}$ avaliaram 42 comerciários pré e pós dois meses de CL. Obteve-se uma melhora em manifestações de dores relatadas 
no período de testes, sendo elas: nas regiões de braços e pescoço, encontrando-se também melhora significativa na diminuição da procura por ajuda médica durante os dois meses de intervenção.

Com a finalidade de avaliar 20 funcionários, de ambos os sexos, da empresa Telemont em Brasília após a CL, Souza e Bezerra ${ }^{30}$ aplicaram um questionário de 30 perguntas aos funcionários praticantes da CL para avaliar o bem estar físico e funcional. Como principais resultados, $95 \%$ dos funcionários relataram uma melhora da flexibilidade após a CL; $90 \%$ afirmaram obter uma melhora significativa na saúde; e $60 \%$ afirmaram que o rendimento no trabalho está vinculado as aulas de CL. Souza e Bezerra ${ }^{30}$ destacaram ainda a grande aceitação e percepção da importância do programa por funcionários e chefes da empresa.

\section{CONCLUSÃO}

De acordo com o presente estudo, foi possível notar que a CL pode interferir beneficamente na qualidade de vida dos trabalhadores, melhorando a saúde e a qualidade de vida, tendo impacto positivo no dia a dia do trabalhador e em sua jornada de trabalho, além de contribuir para a empresa no sentido de maior eficácia no trabalho e redução do absenteísmo e afastamentos médicos.

A redução da dor, a melhora no desempenho e no bem estar são os principais benefícios que a CL pode trazer ao funcionário, comprovando sua eficiência, independente de quantas vezes na semana é executada e o período.

Ainda destaca-se que, além de melhorar os quadro álgicos, a CL ainda melhora o estresse e causa o relaxamento, aspectos necessários para motivar o funcionário a executar bem o seu trabalho.

Com isso, chegamos à conclusão de que ambas as CL trazem resultados positivos, independente do prazo de aplicação (curto, médio e longo prazo). Portanto, um programa de CL bem elaborado, para atender as necessidades do público alvo, tem resultados positivos na qualidade de vida do trabalhador.

\section{REFERÊNCIAS}

1. Benardi DF. Fisioterapia Preventiva em Foco. Rio de Janeiro: Guanabara Koogan; 2010.

2. Merlo ARC, Lápis NL. A saúde e os processos de trabalho no capitalismo: algumas considerações. Boletim Saúde. 2005; 19(1):17-29.

3. Bergamaschi EC, Deustch S, Ferreira EP. Ginástica laboral: Possíveis implicações para as esferas física, psicológica e social. RBAFS. 2002; 7(3):23-9.

4. Gomide ABL. Análise da carga física de trabalho para prevenção da fadiga - um estudo de caso - operador de checkout, 2010. 53f. [dissertação]. Bauru: Universidade Estadual Paulista Júlio Mesquita Filho (UNESP); 2010.

5. Renner JS. Prevenções e distúrbios osteomusculares relacionados ao trabalho. Boletim Saúde. 2005; 19(1):73-80.

6. Campana AO, Padovani CR, Iaria CT, Freitas CBD, De Paiva SAR, Hossne WS. Investigação científica na área médica. Sao Paulo: Manole; 2001.

7. Maciel RH, Albuquerque AMFC, Melzer AC, Leônidas SR. Quem se beneficia dos programas de Ginástica Laboral? Cad psicol soc trab. 2005; 8:71-86.

8. Associação Internacional de Ergonomia. What is Ergonomics? 2000. BRASIL. Ministério do Trabalho. Secretaria de Inspeção do Trabalho. Manual de aplicação da Norma Regulamentadora $\mathrm{n}^{\circ}$ 17. 2. ed. Brasília: MTE, STI, 2002.

9. Braga CO. Análise ergonômica do trabalho e exigências laborais em unidades de beneficiamento de tomate de mesa [dissertação]. Campinas:Faculdade de Engenharia Agrícola (UNICAMP); 2007.

10. Oliveira PAB. Ergonomia e a Organização do trabalho: $O$ papel dos espaços de regulação individual e social na gênese das LER/DORT. Boletim Saúde. 2005; 19(1):31-8.

11. Villarouco V, Andreto LFM. Avaliando desempenho de espaços de trabalho sob o enfoque da ergonomia do ambiente construído. Produção. 2008; 18(3):523-39.

12. Dartora J, Santos MV. Cinesioterapia laboral preparatória para trabalhadores de limpeza e urbanização de uma empresa do Vale do Taquari/RS. Rev Destaques Acadêmicos. 2014; 6(3):196-205.

13. Martins CO. Efeito da ginástica laboral em servidores da reitoria da UFSC [dissertação]. Florianópolis: Universidade Federal de Santa Catarina (UFSC); 2000.

14. Oliveira JRG. A importância da ginástica laboral na prevenção das doenças ocupacionais. Rev Educação Física. 2007; 139:40-9.

15. Pedroso WR, Parizotto ZAM. Ginástica laboral: as perspectivas da sua prática na redução do cansaço físico. Fiep Bulletin; 2015; 85(Spec ed):article 1.

16. Pimenta FAP, Simil FF, Torres HOG, Amaral CFS, Rezende CF, Coelho TO et al . Avaliação da qualidade de vida de aposentados com a utilização do questionário SF-36. Rev Assoc Med Bras. 2008; 54(1):55-60.

17. Engelmann J. A ginástica laboral e a redução de desconforto/dor e tensão muscular em indivíduos que trabalham em uma empresa de desenvolvimento e suporte de software em Ivorti/RS, 2008.

18. Bittencourt JDC, Campos CM, Evangelist JN, Oliveira TS, Santos CL, Ferraz DD. Qualidade de vida dos funcionários de uma empresa de comunicação impressa praticantes da cinésioterapia laboral compensatória. Rev Pesquisa Fisioterapia. 2014; 4(2):114-22.

19. Brito ECO, Martins CO. Percepções dos participantes de programa de ginástica laboral sobre flexibilidade e fatores relacionados a um estilo de vida saudável. Rev Bras Promoç Saúde. 2012; 25(4):445-54.

20. Cadotti CT, Stroschein R, Noll M. Efeito da ginástica laboral na dor nas costas e nos hábitos posturais adotados no ambiente de trabalho. Rev Bras Ciênc Esporte. 2011; 33(3):699-714.

21. Costa DF, Costa EO, Barbosa Rezende AA, Rodrigues ESR, Muniz CF, Rossone AP. A influencia dos três tipos de ginástica laboral na melhora da qualidade de vida. Revista Amazônia. 2013; 1(2):29-36.

22. Gondin KM, Miranda MDC, Guimarães JMX, D'Alencar BP. Avaliação da prática de ginástica laboral pelos funcionários de um hospital público. Rev Rene. 2009; 10(2):95-102.

23. Oliveira AA, Marques NB. A melhoria da qualidade de vida no trabalho em funcionários de produção através da ginástica laboral na Universidade Paulista UNIP. Fiep Bulletin; 2013; 83(Spec ed):article 1.

24. Reis SAM, Sposito LAC, Silva RN, Bueno DGM, Silva E, Rezende JA. Efeito da ginástica laboral em servidores do Instituto Federal do Sul de Minas Gerais - Câmpus Muzambinho. In: Anais da $6^{\text {a Jornada }}$ Científica e Tecnológica do IFSULDEMINAS. Pouso Alegre, MG. 2014.

25. Sakamoto VR, Donatto FF, Navarro AC. A influência da ginastica laboral e da qualidade alimentar empresarial na sintomatologia do quadro de dor em funcionários do setor administrativo. RBNE. 2011; $5(25): 62-9$.

26. Santos EL. A influencia da ginástica laboral na qualidade de vida dos professores e na prática do 
processo de ensino e aprendizagem de ciências [monografia]. Medianeira: Universidade Tecnológica Federal do Paraná (UFTPR); 2013.

27. Sedrez JA, Rosa MIZ, Cunha A, Candotti CT Avaliação dos efeitos de um programa de ginastica laboral, sobre a dor e a qualidade de vida. Cinergis. $2012 ; 13(2): 21-6$

28. Silva AL. O impacto da ginástica laboral na saúde e bem estar docente [trabalho de conclusão de curso]. Ariquemes: Universidade Brasília/Polo AriquemesRR; 2012.

29. Silveira JWP, Laat EF, Pilatti AA, Silva F, Machowski CM, Samila G. Ginástica laboral e prevenção de dores crônicas, Cinergis 2013; 14(2):115-9.

30. Souza HM, Bezerra EO. A importância da ginástica laboral em funcionários da empresa Telemont, na prevenção da LER/DORT [trabalho de conclusão de curso]. Brasília: Universidade Católica de Brasília; 2014.

\section{CONFLITO DE INTERESSES}

Os autores declaram não haver conflitos de interesse.

\section{AUTOR PARA CORRESPONDÊNCIA}

\section{Leandro Iackstet}

dr.iackstet@gmail.com

Submetido em 21/02/2018

Aceito em 27/03/2018 